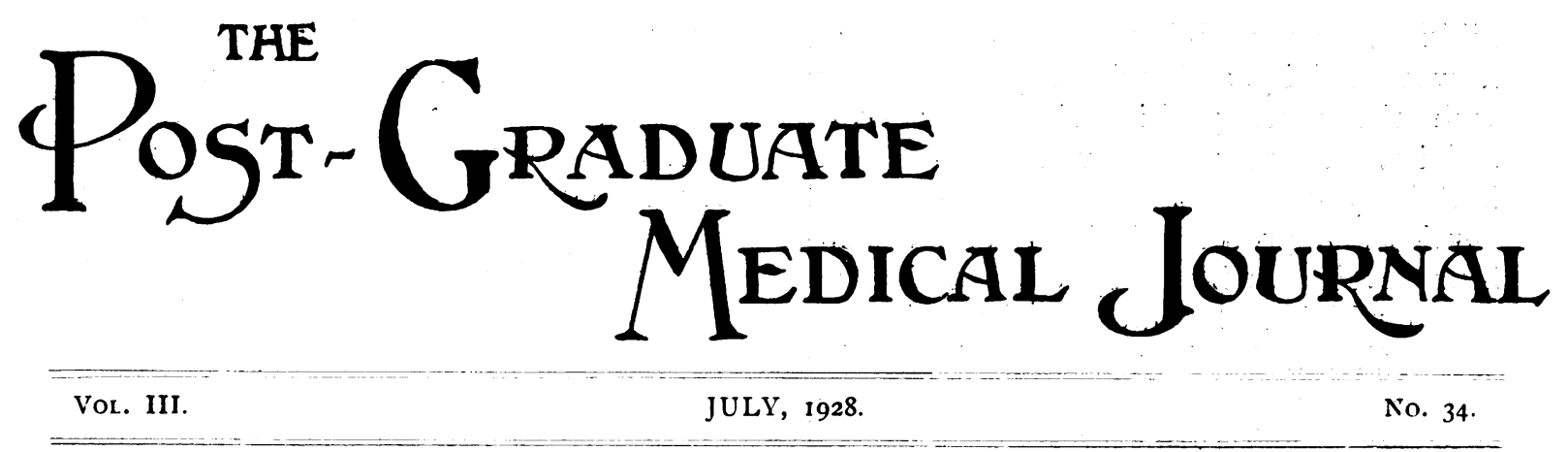

\title{
CONTENTS
}

PAGE

Thf High-grade Mental Defect in Relation to Genfral Practice $\quad \ldots \quad 173$ By J. L. BirI.EY, C.B.E., M.D.

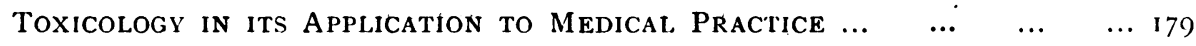

By Sir William Wilicox. K.C.I.E., C.B., C.M.G., M.D., F.R.C.P.

$\begin{array}{llllllllllll}\text { ROUND THE WARDS } & \ldots & \ldots & \ldots & \ldots & \ldots & \ldots & \ldots & \ldots & \ldots & 189\end{array}$

$\begin{array}{llllllllllll}\text { EditoRIAL NOTES } & \ldots & \ldots & \ldots & \ldots & \ldots & \ldots & \ldots & \ldots & \ldots & \ldots & 189\end{array}$

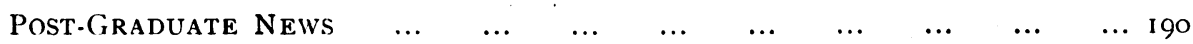

Fellowship of Medicine and Post-Graduate Medical Association.$\begin{array}{lllllllllll}\text { SPECIAL COURSES } \ldots & \ldots & \ldots & \ldots & \ldots & \ldots & \ldots & \ldots & \ldots & \text { iv }\end{array}$

THE HIGH-GRADE MENTAL DEFECT IN RELATION 'TO GENERAL PRACTICE.

\author{
By J. L. BIRLEY, \\ C.B.E., M.D.,
}

Physician to St. Thomas's Hospital.

(A Lecture delivered under the Auspices of the Fcllowship of Medicine and Post-Graduatc Association.)

(Continued from p. 160.)

ON examination, the girl had that curious "woodeny" look that is so characteristic of amentia, although at times she would become animated and angry, particularly when the conversation strayed to subjects which were out of her depth. She refused, for example, to persist in the intelligence tests after finding the first series unexpectedly difficult. Her disposition was pugnacious and aggressive, and it is to be noted that the disposition of aments varies just as does that of normal individuals. In this case the aggressive and self-assertive tendencies were prominent as compared with the instincts of fear and submissiveness. She was, in fact, extraordinarily. fearless, but her fearlessness, uncontrolled by intelligence, was a wasted asset. She had no enduring interests, and consequently had never achieved anything beyond a reputation for being a perpetual nuisance. The question arises, Why were the self-assertive tendencies uncontrolled? because, on the answer depends the whole explanation of the behaviour of individuals of this type. It is sometimes held that the lack of control is due to a defect, and an innate defect, of in- 
hibition. But inhibition is an aspect of all nervous activity, and is developed pari passu with the more positive sides of nervous activity. There is no such thing as an inhibitory centre or centres. As mental development proceeds the inhibitory mechanisms develop in like proportion, and at an age at which the behaviour of a child can be studied it is clear that the instinctive impulses are controlled in a number of ways, all of which are expressions of general intelligence, such as by remembered experiences of pain and fear, by distraction of attention, and so on. Another explanation of uncontrolled conduct is a gross discrepancy between the strength of the emotional tendencies and the strength of the intelligence whereby they are to be controlled. This is a much more difficult problem, and will be referred to later; but, dealing with the case under discussion, it may be argued that, while general intelligence was little below normal, the emotional tendencies had been very unequally developed, so that, whereas the aggressive instincts (anger, selfassertiveness) were prominent, the more inhibitive instincts (tenderness, fear, submissiveness) were atrophic. My own belief is that such a classification of emotional tendencies into two rather watertight compartments is artificial, while I turther believe that the proper development of all instinctive trends depends essentially on the cooperation of intelligence. For example, the aggressive instincts in an individual adequately endowed with intelligence may make for strong character, great achievement, and the satisfaction of ambition; this is effected particularly through the operation of the self-asserting tendency and the sentiment of self-regard derived from it, a tendency which is capable of being built up into enduring sentiments of great power and complexity; but unless diluted, so to speak, with the sentiments which owe their origin to the more inhibitive instincts, makes for strong character rather than for great or good character. Of the inhibitive instincts, that of tender emotion is the most vital, for to its influence may be traced considerateness, all altruistic feeling, love for one's fellow creatures and for animals; in its absence conduct is hard, ruthless and cruel, and without it moral sentiments can never develop at all completely. In the case just referred to we find an example of the lack of the instinct of tender emotion, a hard, selfish person, incapable of kindly feeling or of being swayed by sentiments for abstract moral qualities. She was like a rudderless ship sailing an uncharted sea, her only guide. posts Pleasure and Pain, so that if a thing were pleasant she would seek it, if disagreeable eschew it. Such conduct, I maintain, is the result of imperfect mental development.

Comparison of this case may be made with a girl of $3 \mathrm{I}$, who appears never to have been interested in anything. She remained at school until she was $2 I$, as she was "so childish," but never made any friends, and always preferred the company of children and girls much younger than herself. She had difficulty in writing a letter, spelt very badly, had never bought her own clothes, or had charge of money, and generally had. proved unable to fend for herself. Beyond occasional outbreaks of temper she was of a nice quiet disposition, and for many years had been content to live at a boarding house in the country, doing the washing up. Her intelligence rating was under $\mathbf{I} 2$, and her general emotionality very much undeveloped. She realized she was not like other people, and ascribed it, as did her guardians, to laziness. My diagnosis of feeble-mindedness was ill received by her relations, who had for years been goading her on to activities of which she was fundamentally incapable, and I have no doubt that if the diagnosis had been made earlier the patient would have been spared much unhappiness, particularly that which comes from persistently competing against people of higher intellectual attainments than one's self.

This case is an example of the general correlation which exists between all mental 
activities; intelligence and emotional tendencies were both retarded with the result that the patient was dull and devoid of desire.

A somewhat unusuat manner in which the question of mental fitness may arise in prac. tice is illustrated by the following case. Not long ago I was asked to give an opinion as to the advisability of terminating a pregnancy on the grounds of the mother's mental health. At the time of the interview I knew and was able to elicit no details of the family history. It was, however, brought to my knowledge that in the previous two pregnancies the patient had been very difficult, and further that she had shown very little affection for either of her children. The patient, aged 32, at once disclosed by her statements an obvious lack of maternal affection; it was not so much the inconvenience of having a baby as her utter indifference to children which was prompting her attempt to have the pregnancy terminated. I found her to be incapable of any abstract reasoning, devoid of constructive imagination and enthusiasm, without any convictions, and extremely limited in her ideas; she was leading an aimless existence, unable to take any interest in anything except her own comforts; she was also devoid of all sense of humour. I had no doubt at all that she was a moron.

It later transpired that her brother was a "bad hat," that her sister's only child was imbecile, and that a paternal aunt had two defective children. Moreover, of her own children one was definitely feeble-minded and the other doubtfully so. The advice given was to terminate the pregnancy and to sterilize the patient. This woman was a member of the wealthy class, married to a highly intelligenit, altruistic and successful man, who accepted and endorsed the diagnosis. The case serves to show that the moron, particularly if the circumstances are easy, can pass muster and parade as an ordinary if somewhat uninteresting and useless member of a society which ought to regard such individuals as a menace.
In none of the patients so far studied have there been examples of definitely immoral behaviour, and largely on that account none of them had been recognized as being feeble-minded until a relatively late age. They had been regarded as neurasthenic, lazy or difficult. We may now pass on to consider briefly one or two cases in which disregard of moral codes has been a conspicuous feature, a disregard which is so distressing to the parents that the patients are brought to a doctor at a relatively early age.

Girl, aged 14, of highly-gifted stock. Her mother was ill during the pregnancy, but labour was uneventful. Aged 3, she first began to make inarticulate noises to indicate her wants; she was also very back-. ward in walking. A confirmed nail-biter and impulsive. Aged 8, found to be stealing; threw her nurse's watch out of a window to conceal its theft. Aged 9, very untruthful, would steal nibs and fountain pens and hoard them. Aged I I, her elder brother died but she exhibited no sign of sorrow. At that time she was put on thyroid and improved, and is now said to be up to the average as regards intelligence. She still, however, opens other people's letters and writes extracts from them into her own diary; has a craving for sweets and will do anything to satisfy it. Children of her own age ignore her, and towards younger children she is autocratic, bullying and at times cruel. She is cruel also to animals if they are defenceless.

Punishment has never acted as a deterrent, and such traces of contrition as she has shown have been short-lived. If left to herself she does absolutely nothing, never reads with the exception of forbidden books and detective stories. She prefers to have her meals alone, and always eats better when this wish is granted. She resented being examined, and when asked to describe a perfect day was unable to say more than that she would begin with toffee. Her physique was normal, her features coarse, her face expressionless, and her gait clumsy and awkward. The girl had been wisely treated by her parents, and there was no reason for supposing that her peculiarities were due to faults of environment or upbringing. 
This case is of considerable interest, and we will begin by examining the explanation advanced by one of her parents, viz., that the girl was born without a moral sense, an explanation which implied as a corollary that normal individuals are born with a moral sense. Such a view, however, is manifestly incorrect, for it implies in the first place that the moral sense whereby we recognize what is good and praiseworthy is comparable to the sense of sight whereby we recognize colours and shapes. But such sense conception is an extremely complex affair and cannot possibly rest on any innate tuition. Secondly, it may be very comforting to some people to believe that we are born with a sense of right and wrong, but it is nevertheless untrue; we learn the difference, and the lesson can be learnt only with the aid of intelligence. So much is this the case that supposing everyone above the age of 4 were to be exterminated, we should automatically revert to the earliest phases of culture both concrete and abstract. The foundations of a man's character rest, it is true, on certain innate dispositions, but moral character as such is not inborn, and as $\mathrm{Mr}$. Cyril Burt has truly said, "If a moral imbecile is to be defined as a person born without a moral sense, then we are all moral imbeciles." McDougall has put forward the view that the development of moral ideas is to be traced to the elaboration of impulses derived from the instinct of tender emotion, and that it is through the operation of our self-regarding sentiment that our moral strivings are activated and made effective. The development of our moral character is further promoted by the operation of primitive sympathy, the einotional associate of the gregarious instinct, which, while not primarily prompting us to social behaviour, gives men, by drawing them together, greater opportunities for acquiring such behaviour.

With the views propounded by McDougall I am in complete agreement, and reference to the history of the previous case suggests that the patient was particularly lacking in those very sentiments by the aid of which moral character is formed. For example, the absence of grief for her dead brother, and her cruelty towards children and animals, display a defect of the tender emotion; her preference for loneliness and for eating alone indicates a lack of primitive sympathy, while her lack of self-respect is illustrated by her incapacity to feel regret for her uncontrolled acquisitive tendencies.

For several years it has been one of my most interesting but difficult duties to examine the girls who pass through a hostel attached to one of the great London hospitals. One finds that a great majority of these girls give a history indicative of instability from an early age, many of them in spite of what appears to have been a healthy and helpful environment. $A$ few of them are manifestly feeble-minded and certifiable as such, but it is otherwise with the majority, one example of which will suffice.

Girl, aged 23. Father alcoholic and eventually committed suicide. His wife left him when the patient was two years old, remarried happily and had five healthychildren. The patient's own sister is a nun in a secluded order. She walked, aged 4 , and was very backward in talking. She went to a Convent School, and was reported as being " passionate, jealous, suspicious, dishonest and untruthful, and a glutton for sweets." Aged 8, she went into a baker's shop, pleaded starvation and was given a loaf which she promptly sold to a neighbour. After leaving school she would go to shops; where the parents had accounts, and order cakes, sweets and shoes and clothes. She steals her parents' belongings and sells them, and her thefts show much cunning and planning. She is very boastful, likes to give presents at other people's expense, and gloats over seeing her step-sisters punished for her misdoings. After teaching in a Convent Kindergarten, she suddenly announced that she had accepted a post at $£ 5^{\circ}$ per annum as nursery governess to an English family in Spain, whither she went and remained for a year. On her return she was met by friends at Gibraltar, but evaded 
them and spent some days with a man. On arrival in England, she went as a maid to a hotel, and some months later was admitted to the hostel, three months pregnant and suffering from a gonococcal infection. On examination the girl was extremely plausible, showed no remorse for her misdeeds, said she found stealing amusing and was looking forward to leading a "free life." The fact that she was infectious did not bother her one bit. She had no reasoning powers, no scruples, and was apparently incapable of showing affection. An attempt to have the girl certified broke down on some technical point much to my disgust. She was over 2I years of age, and not in receipt of poor relief ; but if cases of this kind cannot be dealt with under the Act, how are they to be dealt with? One is sometimes told that from the point of view of intelligence the patients are not bad enough, but surely it is just this type of moron that provides the greatest danger to the community. Again it is sometimes argued that it has not been proved that "punishment has no deterrent effect," but how is one to punish a girl of this kind? She would merely laugh and repeat the offence as soon as your back was turned.

Putting aside all legal definitions as to the nature of mental defect, and as to the degree of defect necessary to justify certification, it seems to me reasonable to suppose that the last patient, who might perhaps have "got through " on an intelligence test, is, from the psychological point of view, just as much a case of mental defect as the others. That her defect was innate is shown by her backwardness and history. However much "fun" she had got out of life it cannot be said that she had displayed either prudence or wisdom in her own interest or in other people's. Her defect lies in the very imperfect development of the inhibitive tendencies, viz., fear, submission, tenderness and disgust, and it is interesting to observe that for the proper development of enduring sentiments the co-operation of intelligence is perhaps more essential in the case of the inhibiting instincts than it is in the more self-seeking ones of anger, acquisitiveness and sex. In fact it may be doubted whether the sexual instinct, without the co-operation of welldeveloped sentiments derived from the instinct of tender emotion and other innate tendencies, is capable of giving rise to any organized and enduring attitude other than that of physical desire. The fact that the immense energy inherent in the sexual instinct is capable of sublimation and thus of expressing itself in artistic pursuits does not militate against this view, for the process of sublimation is not confined to this instinct and is itself an expression of the workings of intelligence. It would also appear that one of the essential defects in cases of what is wrongly called moral imbecility consists in an inability to blend the primary emotional qualities with one another. For example, such emotional experiences as admiration, pity, repugnance and reverence, are to a great extent a closed book to the high-grade defective, and, if experienced at all, are experienced on a somewhat debased level, and the same applies to the still more elaborate varieties of feeling called the derived emotions, such as hope, joy, and sorrow. Now it is through the greater development of imagination that the existence of such an emotional experience as, for example, reverence, becomes at all possible. But imagination is merely an aspect of the working of intelligence, and it is owing to our capacity for thinking of remote objects and experiences, a capacity enormously augmented by the development of language, that we become capable of abstract reasoning. It is just because the feeble-minded person is unable to reason in this way that he is unable to think about those primarily abstract qualities which we call moral, and so to form concrete sentiments about them ; judgment and wisdom cannot flourish in the absence of all moral feeling. The desires of the defective remain on a primitive basis and he cannot work successfully and assiduously in the service of any object owing to his inability to be sustained by any enduring sentiment for that object; or, to put it colloquially, he has no enduring interests. 
In conclusion; let me repeat once more that the high grades of defect provide a much more difficult and much bigger. problem from every point of view, psychological and sociological, than the low grades. Sterilization would only touch the bare fringe of the subject, for the moron is a nuisance and a menace to the community, not only because of his potential powers for evil in the future, but for what he is to-day. It is true that he often makes work for other people, but the work is unproductive and the energy so expended could be better employed elsewhere. He is further dangerous in so far as he often escapes detection, and in this respect those of you who are in general practice can give very material assistance. I am convinced that if the terms " neurasthenia" and "functional" were eradicated from medical books and conversation we should be better equipped for recognizing the high-grade defect. I am further prepared to believe that in far more cases than we Have ever been led to suppose the basis of hysteria is in the nature of a defect of mind, and the complacent and smug satisfaction with which many hysterics view their crude and pathetic solutions of petty difficulties seems to lend support to this opinion. Nor should I be vastly surprised if, in the years to come, some of the neuroses are traced to inherent defects. In dealing with the nature of mental defect I have deliberately avoided confining the discussion within the limits of legal definition, for all such definitions must be arbitrary, but this method has been selected purely for the sake of convenience and not because I have any quarrel with the legal definitions now in force. It has been pointed out that an innate defect can only apply to those mental functions which themselves are innate and, for our present purposes, these are two in number, namely, what is called general intelligence and certain fundamental or instinctive emotional tendencies. The main argument of this lecture has been that these two aspects of mental activity show a general correlation and that they are mutually interdependent for their proper development and growth. It has however been admitted that the fundamental tendencies may be very unequally developed in different individuals, as indeed they are in different races; this in itself, however, is not sufficient justification for designating the resulting condition a mental defect. It is only when this unequal development is associated with an impairment of general intelligence that the diagnosis of mental defect can confidently be made. In this respect stress has been laid on the fact that for the proper growth of those fundamental tendencies from which are derived sentiments making for proper social beliaviour, the co-operation of intelligence has a wider sphere of influence than is the case with the more aggressive instincts of sex, anger and acquisition. Moreover, the blending of the primary emotional qualities which occurs in the normal individual, owing to the fact that through the operation of imagination he is liable to be moved simultaneously by more than one impulse, is curiously lacking in the defective, with the result that he is swayed and governed by the more primitive emotions at the expense of the more elaborate or derived emotions. Further; reason, although not in itself the primary stimulus to activity, in the normally endowed individual enormously widens the field of conduct by evoking new impulses or by modifying in one direction or another an impulse already in operation. The conduct of the defective is abnormal partly owing to his inability to reason and also because his emotional tendencies are imperfectly or unequally developed, with the result that such reasoning powers as he may possess have a much narrower field in which to work. Finally, it is owing just as much? to the intimate interdependence of general intelligence and instinctive trends as to the great difficulty of defining "general intelli- $\mathbb{D}$ gence," that intelligence tests, however useful they may be as confirmatory evidence, can- $\Omega$ not be regarded as the sole and decisive fac- 
tor in determining the presence or degree of mental defect. Conduct, and in practice this implies an accurate history of the patient from an early age, is still the best intelligence test at our disposal, and it should be remembered that the slighter the degree of defect the greater will be the age at which conduct and behaviour begin to show evidence of abnormality.

\section{TOXICOLOGY IN ITS APPLICATION TO MEDICAL PRACTICE.}

\section{By SiR WILliaM WILLCOX,}

K.C.I.E., C.B., C.M.G., M.D., F.R.C.P.

"THE HARVEIAN LECTURE" DELIVERED BEFORE THE HARVEIAN SOCIETY, ON THURSDAY, MARCH $15,1928$.

THE Harveian Lectures of the Harveian Society were instituted in 1875 , in which year the first lecture was given by Dr. Sibson, F.R.S., "On Bright's Disease and its Treatment: Considered mainly in Relation with Arterial Tension from Blood Contamination."

Harveian Lectures have since that date been given annually by members of the medical profession selected by the Council of the Harveian Society. The list includes the honoured names of many of the wellknown leaders of the medical profession of their day, and the titles of the lectures include a wide diversity of most important subjects in medical science.

Toxicology has not yet formed one of the subjects of the lectures and it is therefore fitting that the fifty-fourth lecture should be devoted to this branch of medicine.

Toxicology has, from the earliest times, been a branch of medicine which has had a fascinating attraction, for it deals with the action of poisons on the body, and sometimes the toxicologist has been called upon to unravel the hidden mystery of the cause of death in some famous criminal trial.
Toxicology has always been a very important branch of medicine because of its relationship to the legal aspects of medicine, and it will always retain this position.

In modern times, toxicology has attained a position of the utmost importance in its relationship to medicine, and has become so closely interwoven with scientific medicine as to form an intimate and inseparable part.

The studies of Pasteur in 1860 formed the foundation of bacteriology, and the development of this branch of pathology has elucidated the cause of many diseases.

It is now recognized that the symptoms of disease are usually due to the development of toxins or poisons in the body. These poisons are in some cases produced by the entrance into the body of germs from without which by their growth produce toxins, as occurs in pathogenic diseases such as typhoid, tuberculosis, diphtheria, \&c., where the invading causal organism is known.

In recent years, the development of the theory of "focal infection" has shown that an important factor in the causation of many pathological conditions, such as chronic rheumatism, gastric and duodenal ulceration, diabetes, \&c., is the production of toxins or poisons in the body at some localized focus, such as infected teeth, septic tonsils, infected nasal sinuses, \&c.

These toxins, by their distribution into the circulation, may set up some disease in parts of the body far distant from the originating focus of infection.

In other cases, owing to impairment of the function of organs which are of importance in the body economy either for excreting toxic substances or for regulating its metabolism, toxins are produced which give rise to symptoms known as auto-intoxication.

Examples of this are the symptoms of uræmia produced by defective renal action, or the symptoms of auto-intoxication resulting from impaired function of other organs, such as the liver, suprarenal glands, pancreas, \&c. 